\title{
Schoolverlaters-Meting 2019: Kernresultaten
}

Citation for published version (APA):

Meng, C. (2020). Schoolverlaters-Meting 2019: Kernresultaten. ROA. ROA Fact Sheets No. 007 https://doi.org/10.26481/umarof.2020007

Document status and date:

Published: 19/10/2020

DOI:

10.26481/umarof.2020007

Document Version:

Publisher's PDF, also known as Version of record

\section{Please check the document version of this publication:}

- A submitted manuscript is the version of the article upon submission and before peer-review. There can be important differences between the submitted version and the official published version of record.

People interested in the research are advised to contact the author for the final version of the publication, or visit the DOI to the publisher's website.

- The final author version and the galley proof are versions of the publication after peer review.

- The final published version features the final layout of the paper including the volume, issue and page numbers.

Link to publication

\footnotetext{
General rights rights.

- You may freely distribute the URL identifying the publication in the public portal. please follow below link for the End User Agreement:

www.umlib.nl/taverne-license

Take down policy

If you believe that this document breaches copyright please contact us at:

repository@maastrichtuniversity.nl

providing details and we will investigate your claim.
}

Copyright and moral rights for the publications made accessible in the public portal are retained by the authors and/or other copyright owners and it is a condition of accessing publications that users recognise and abide by the legal requirements associated with these

- Users may download and print one copy of any publication from the public portal for the purpose of private study or research.

- You may not further distribute the material or use it for any profit-making activity or commercial gain

If the publication is distributed under the terms of Article $25 \mathrm{fa}$ of the Dutch Copyright Act, indicated by the "Taverne" license above, 


\section{Maastricht University $\&$ ROA}

\section{Schoolverlaters-Meting 2019: Kernresultaten}

Christoph Meng

\section{ROA Factsheet}

ROA-F-2020/7

Researchcentrum voor Onderwijs en Arbeidsmarkt | ROA Research Centre For Education and the Labour Market / ROA 


\section{Schoolverlaters-Meting 2019: Kernresultaten}

\section{Leeswijzer}

\section{A) Een viertal monitoren}

De in dit document gepresenteerde tabellen bevatten de kerncijfers afkomstig van de schoolverlaters en afgestudeerden onderzoeken uitgevoerd in het najaar van 2019.

- VO-Monitor: Onderzoek onder gediplomeerden van het vmbo, het havo en het vwo. De respondenten hebben hun diploma in het schooljaar 2017-2018 ontvangen. De VO-Monitor wordt door het CBS (in samenwerking met het ROA) uitgevoerd.

- BVE-Monitor: Onderzoek onder de gediplomeerden van het mbo (bol en bbl). De respondenten hebben hun diploma in het schooljaar 2017-2018 ontvangen. De BVE-Monitor wordt door het CBS (in samenwerking met het ROA) uitgevoerd.

- HBO-Monitor: Onderzoek onder de afgestudeerden van het hbo. De respondenten hebben hun diploma in het academisch jaar 2017-2018 ontvangen. De gepresenteerde cijfers hebben daarbij betrekking op afgestudeerden van voltijdopleidingen. De HBO-Monitor wordt onder auspiciën van de Vereniging Hogescholen en in opdracht van de hogescholen door het ROA in samenwerking met DESAN Research Solutions uitgevoerd.

- NAE: Onderzoek onder de afgestudeerden van het wo. De respondenten hebben hun diploma in het academisch jaar 2017-2018 ontvangen. De gepresenteerde cijfers hebben daarbij betrekking op afgestudeerden van voltijd masteropleidingen. De NAE wordt in opdracht van de VSNU door Desan Research Solutions uitgevoerd. We danken de VSNU voor het beschikbaar stellen van de resultaten hiervan.

\section{B) Vergelijkbaarheid tussen monitoren}

Door marginale verschillen in de vragenlijsten, zijn uitkomsten niet altijd één op één vergelijkbaar tussen de monitoren. De lezer dient dan ook nadrukkelijk bij de interpretatie van de uitkomsten met de onderstaande definities en verschillen tussen de monitoren rekening te houden.

\section{C) Definities}

\section{Tabellen: Algemeen}

1. Oordeel van de gevolgde opleiding als basis om te starten op de arbeidsmarkt/basis om kennis en vaar- digheden verder te ontwikkelen: \% antwoordcategorie 4 of 5 op een 5 -punt Likert schaal

Definitie: \% dat aangeeft dat opleiding/studie een goede/zeer goede basis was om te starten op de arbeidsmarkt.

Definitie: \% dat aangeeft dat opleiding/studie een goede/zeer goede basis was om kennis en vaardigheden verder te ontwikkelen.

2. Opleiding achteraf opnieuw kiezen: $\% \mathrm{Ja}$

Definitie: \% dat aangeeft dat ze de gevolgde opleiding opnieuw zouden kiezen.

Let op: Door een verschil in de vraagstelling is de uitkomst niet vergelijkbaar tussen VO- en BVE-Monitor enerzijds en HBO-Monitor/NAE anderzijds.

3. Oordeel over opleiding was uitdagend qua niveau: $\%$ antwoordcategorie 4 of 5 op een 5 -punt Likert schaal Definitie: \% dat mee eens/helemaal mee eens is dat niveau van de opleiding uitdagend was.

\section{Tabellen: Vervolgopleiding}

1. Aansluiting tussen gevolgde opleiding en vervolgopleiding: \% goed/redelijk

Definitie: \% dat de aansluiting tussen gevolgde opleiding en vervolgopleiding voldoende of goed vindt.

2. Gestopt: \% Ja

Definitie: \% dat met vervolgopleiding op moment van enquête alweer gestopt is en op moment van enquête niet in het onderwijs ingeschreven staat (BVE-Monitor) dan wel aangeeft geen studie te volgen (HBO-Monitor/NAE).

3. Gestopt en van studie gewisseld: $\%$ ja

Definitie: \% dat met vervolgopleiding op moment van enquête alweer gestopt is en op moment van enquête in het onderwijs in een andere opleiding ingeschreven staat (BVE-Monitor) dan wel aangeeft een studie te volgen (HBO-Monitor/NAE).

\section{Tabellen: Arbeidsmarkt}

\section{Let op:}

Door wijzigingen in de BVE-monitor vragenlijst is de beslissing genomen om de definitie van de beroepsbevolking voor de gediplomeerden van het mbo vanaf meetjaar 2019 (licht) te wijzigen en deze in lijn te brengen met de definitie zoals door het CBS 


\section{Factsheet}

gehanteerd. De definitie van de beroepsbevolking voor de gediplomeerden van het mbo is niet meer identiek aan de definitie van de beroepsbevolking van de afgestudeerden van het hbo en het wo. De lezer dient dan ook rekening te houden dat arbeidsmarktcijfers tussen mbo aan de ene kant en hbo/wo aan de andere kant niet 1:1 vergelijkbaar zijn.

1. Werkzaam op eigen niveau: $\%$ Ja

Definitie: respondent geeft aan dat voor het werk dat hij of zij uitvoert minimaal een diploma op het eigen onderwijsniveau vereist is. Hierbij wordt een HBO-Bachelor qua niveau gelijk gesteld met een WO-Bachelor en een HBO-Master qua niveau gelijk gesteld met een WO-Master.

2. Werkzaam in eigen domein: $\% \mathrm{Ja}$

Definitie: respondent geeft aan dat voor het werk dat hij of zij uitvoert de eigen, dan wel een verwante, opleidingsrichting het beste voorbereidt.

3. Aansluiting tussen gevolgde opleiding en arbeidsmarktfunctie: \%goed/voldoende:

Definitie: \% dat aangeeft dat de aansluiting tussen gevolgde opleiding en functie voldoende of goed is.

4. Werkloze beroepsbevolking: \% Werkloos

Definitie BVE-Monitor: Een respondent wordt als werkloos geclassificeerd als hij of zij:

- Zich op de arbeidsmarkt aanbiedt;

- Niet in het onderwijs ingeschreven staat;

- Niet werkzaam is (=o uur);

- In de afgelopen 4 weken actief naar werk heeft gezocht;

- Binnen 2 weken beschikbaar is voor werk.

Definitie HBO-Monitor/NAE: Een respondent wordt als werkloos geclassificeerd als hij of zij:

- Zich op de arbeidsmarkt aanbiedt;

- Zich niet als student ziet;

- Niet werkzaam is (= o uur)

- Op zoek is naar werk.

5. Gemiddeld bruto uurloon

Definitie: Bruto uurloon in Euro op basis van maandsalaris en aantal uren werkzaam in hoofdfunctie. 


\title{
Schoolverlaters-Meting 2019: Kernresultaten
}

\author{
Tabellenset
}

\section{A) VO- en BVE-Monitor}

\begin{tabular}{|c|c|c|c|c|c|}
\hline & & $\begin{array}{l}\text { Gevolgde opleiding } \\
\text { achteraf: starten op } \\
\text { arbeidsmarkt } \\
\%\end{array}$ & $\begin{array}{l}\text { Gevolgde opleiding } \\
\text { achteraf: verder } \\
\text { ontwikkelen } \\
\%\end{array}$ & $\begin{array}{c}\text { Opleiding achteraf } \\
\text { opnieuw kiezen } \\
\text { \% }\end{array}$ & $\begin{array}{c}\text { Opleiding was uitdagend } \\
\text { qua nivea } \\
\%\end{array}$ \\
\hline VMBO Totaal & Totaal & & 58 & 68 & 34 \\
\hline \multirow[t]{4}{*}{ VMBO Naar leerweg } & Theoretisch & & 58 & 72 & 32 \\
\hline & Gemengd & & 60 & 66 & 36 \\
\hline & Kaderberoepsgericht & & 60 & 67 & 35 \\
\hline & Basisberoepsgericht & & 56 & 63 & 35 \\
\hline \multirow[t]{5}{*}{ VMBO naar sector } & Landbouw & & 59 & 64 & 34 \\
\hline & Techniek & & 63 & 69 & 40 \\
\hline & Economie & & 61 & 64 & 34 \\
\hline & Gezondheidszorg & & 57 & 66 & 37 \\
\hline & Intersectoraal & & 54 & 63 & 31 \\
\hline MBO Totaal & Totaal & 60 & 63 & 67 & 37 \\
\hline BOL Totaal & Totaal & 57 & 61 & 65 & 35 \\
\hline BOL niveau 1 Totaal & Totaal & 53 & 61 & 57 & 40 \\
\hline \multirow[t]{4}{*}{ BOL 1} & Landbouw & 42 & 58 & 58 & 43 \\
\hline & Techniek & 56 & 63 & 59 & 46 \\
\hline & Economie & 47 & 56 & 57 & 33 \\
\hline & Gezondheidszorg & 56 & 65 & 56 & 42 \\
\hline BOL niveau 2 Totaal & Totaal & 49 & 57 & 54 & 30 \\
\hline \multirow[t]{4}{*}{ BOL 2} & Landbouw & 38 & 51 & 51 & 29 \\
\hline & Techniek & 47 & 59 & 58 & 36 \\
\hline & Economie & 53 & 59 & 54 & 31 \\
\hline & Gezondheidszorg & 47 & 56 & 53 & 26 \\
\hline BOL niveau 3 Totaal & Totaal & 58 & 59 & 63 & 40 \\
\hline \multirow[t]{5}{*}{ BOL 3} & Landbouw & 48 & 54 & 58 & 34 \\
\hline & Techniek & 62 & 59 & 66 & 43 \\
\hline & Economie & 49 & 55 & 54 & 35 \\
\hline & Gezondheidszorg & 69 & 66 & 70 & 47 \\
\hline & Gedrag en maatschappij & 65 & 59 & 68 & 38 \\
\hline B0L niveau 4 Totaal & Totaal & 59 & 62 & 70 & 34 \\
\hline \multirow[t]{5}{*}{ BOL 4} & Landbouw & 51 & 57 & 63 & 35 \\
\hline & Techniek & 61 & 62 & 71 & 37 \\
\hline & Economie & 51 & 61 & 66 & 29 \\
\hline & Gezondheidszorg & 70 & 67 & 75 & 41 \\
\hline & Gedrag en maatschappij & 60 & 61 & 72 & 30 \\
\hline BBL Totaal & Totaal & 70 & 69 & 73 & 43 \\
\hline BBL niveau 1 Totaal & Totaal & 58 & 64 & 64 & 47 \\
\hline \multirow[t]{4}{*}{ BBL 1} & Landbouw & 45 & 58 & 62 & 57 \\
\hline & Techniek & 56 & 63 & 62 & 43 \\
\hline & Economie & 63 & 63 & 63 & 40 \\
\hline & Gezondheidszorg & 63 & 71 & 67 & 55 \\
\hline BBL niveau 2 Totaal & Totaal & 65 & 66 & 70 & 42 \\
\hline BBL 2 & Landbouw & 61 & 68 & 70 & 44 \\
\hline
\end{tabular}




\section{Factsheet}

ROA-F-2020/7

\begin{tabular}{|c|c|c|c|c|c|}
\hline & & $\begin{array}{l}\text { Gevolgde opleiding } \\
\text { achteraf: starten op } \\
\text { arbeidsmarkt } \\
\%\end{array}$ & $\begin{array}{l}\text { Gevolgde opleiding } \\
\text { achteraf: verder } \\
\text { ontwikkelen } \\
\%\end{array}$ & $\begin{array}{c}\text { Opleiding achteraf } \\
\text { opnieuw kiezen } \\
\text { \% }\end{array}$ & $\begin{array}{l}\text { Opleiding was uitdagend } \\
\text { qua nivea } \\
\%\end{array}$ \\
\hline & Techniek & 69 & 66 & 76 & 45 \\
\hline & Economie & 63 & 65 & 63 & 34 \\
\hline & Gezondheidszorg & 63 & 65 & 64 & 45 \\
\hline BBL niveau 3 Totaal & Totaal & 72 & 71 & 73 & 44 \\
\hline \multirow[t]{5}{*}{ BBL 3} & Landbouw & 66 & 65 & 69 & 38 \\
\hline & Techniek & 72 & 69 & 78 & 44 \\
\hline & Economie & 63 & 62 & 60 & 34 \\
\hline & Gezondheidszorg & 80 & 79 & 78 & 50 \\
\hline & Gedrag en maatschappij & 80 & 75 & 83 & 55 \\
\hline BBL niveau 4 Totaal & Totaal & 75 & 71 & 77 & 44 \\
\hline \multirow[t]{5}{*}{$\mathrm{BBL} 4$} & Landbouw & 67 & 66 & 67 & 38 \\
\hline & Techniek & 75 & 76 & 82 & 52 \\
\hline & Economie & 66 & 60 & 66 & 30 \\
\hline & Gezondheidszorg & 81 & 74 & 79 & 46 \\
\hline & Gedrag en maatschappij & 78 & 70 & 79 & 44 \\
\hline
\end{tabular}




\section{Schoolverlaters-Meting 2019: Kernresultaten}

\begin{tabular}{|c|c|c|c|c|}
\hline & & $\begin{array}{c}\text { Aansluiting goed/redelijk } \\
\%\end{array}$ & $\begin{array}{l}\text { Gestopt } \\
\%\end{array}$ & $\begin{array}{c}\text { Gestopt en studie gewisseld } \\
\%\end{array}$ \\
\hline HAV0/VW0 Totaal & Totaal & 79 & 5 & 20 \\
\hline HAVO & & 73 & 7 & 22 \\
\hline vwo & & 88 & 2 & 16 \\
\hline VMBO Totaal & Totaal & 71 & 2 & 10 \\
\hline \multirow[t]{4}{*}{ VMBO Naar leerweg } & Theoretisch & 69 & 2 & 11 \\
\hline & Gemengd & 67 & 2 & 11 \\
\hline & Kaderberoepsgericht & 71 & 2 & 12 \\
\hline & Basisberoepsgericht & 75 & 4 & 7 \\
\hline \multirow[t]{5}{*}{ VMB0 naar sector } & Landbouw & 69 & 3 & 5 \\
\hline & Techniek & 75 & 1 & 6 \\
\hline & Economie & 70 & 2 & 15 \\
\hline & Gezondheidszorg & 74 & 2 & 10 \\
\hline & Intersectoraal & 70 & 3 & 13 \\
\hline MBO Totaal & Totaal & 71 & 7 & 6 \\
\hline BOL Totaal & Totaal & 70 & 7 & 6 \\
\hline BOL niveau 1 Totaal & Totaal & 83 & 4 & 6 \\
\hline \multirow[t]{4}{*}{ BOL 1} & Landbouw & $x$ & $x$ & $x$ \\
\hline & Techniek & 81 & 4 & 9 \\
\hline & Economie & 81 & 3 & 5 \\
\hline & Gezondheidszorg & 85 & 4 & 5 \\
\hline BOL niveau 2 Totaal & Totaal & 80 & 5 & 5 \\
\hline \multirow[t]{4}{*}{ BOL 2} & Landbouw & 74 & 9 & 1 \\
\hline & Techniek & 82 & 5 & 2 \\
\hline & Economie & 80 & 5 & 6 \\
\hline & Gezondheidszorg & 80 & 5 & 7 \\
\hline BOL niveau 3 Totaal & Totaal & 76 & 5 & 2 \\
\hline \multirow[t]{5}{*}{ BOL 3} & Landbouw & 74 & 4 & 2 \\
\hline & Techniek & 75 & 5 & 2 \\
\hline & Economie & 76 & 5 & 2 \\
\hline & Gezondheidszorg & 78 & 4 & 1 \\
\hline & Gedrag en maatschappij & 76 & 5 & 1 \\
\hline BOL niveau 4 Totaal & Totaal & 61 & 9 & 8 \\
\hline \multirow[t]{5}{*}{ BOL 4} & Landbouw & 55 & 10 & 6 \\
\hline & Techniek & 61 & 10 & 8 \\
\hline & Economie & 62 & 9 & 10 \\
\hline & Gezondheidszorg & 60 & 8 & 5 \\
\hline & Gedrag en maatschappij & 60 & 10 & 8 \\
\hline BBL Totaal & Totaal & 80 & 4 & 2 \\
\hline BBL niveau 1 Totaal & Totaal & 82 & 7 & 3 \\
\hline BBL niveau 2 Totaal & Totaal & 86 & 3 & 3 \\
\hline BBL niveau 3 Totaal & Totaal & 80 & 3 & 1 \\
\hline BBL niveau 4 Totaal & Totaal & 58 & 4 & 3 \\
\hline
\end{tabular}




\section{Factsheet}

ROA-F-2020/7

Arbeidsmarkt

\begin{tabular}{|c|c|c|c|c|c|c|}
\hline & & $\begin{array}{c}\text { Minimaal op eigen } \\
\text { niveau } \\
\%\end{array}$ & $\begin{array}{c}\text { Eigen/verwante } \\
\text { richting } \\
\%\end{array}$ & $\begin{array}{c}\text { Aansluiting } \\
\text { goed/voldoende } \\
\%\end{array}$ & $\begin{array}{c}\text { Werkloze } \\
\text { beroepsbevolking } \\
\%\end{array}$ & $\begin{array}{c}\text { Gemiddeld } \\
\text { bruto uurloon } \\
€\end{array}$ \\
\hline MBO Totaal & Totaal & 80 & 68 & 77 & 3,3 & 12,52 \\
\hline BOL Totaal & Totaal & 80 & 64 & 71 & 4,5 & 11,29 \\
\hline BOL niveau 1 Totaal & Totaal & 73 & 36 & 67 & 15,9 & 8,72 \\
\hline BOL niveau 2 Totaal & Totaal & 75 & 49 & 64 & 6,3 & 9,07 \\
\hline \multirow[t]{4}{*}{ BOL 2} & Landbouw & 72 & 43 & 59 & 7,6 & 8,16 \\
\hline & Techniek & 79 & 57 & 61 & 5,2 & 9,05 \\
\hline & Economie & 73 & 47 & 66 & 6,5 & 9,02 \\
\hline & Gezondheidszorg & 77 & 49 & 66 & 6,3 & 9,49 \\
\hline BOL niveau 3 Totaal & Totaal & 76 & 67 & 73 & 4,4 & 11,08 \\
\hline \multirow[t]{5}{*}{$\mathrm{BOL} 3$} & Landbouw & 64 & 48 & 58 & 2,5 & 9,12 \\
\hline & Techniek & 70 & 67 & 70 & 4,1 & 11,13 \\
\hline & Economie & 70 & 53 & 63 & 8,8 & 9,63 \\
\hline & Gezondheidszorg & 82 & 76 & 82 & 1,6 & 12,20 \\
\hline & Gedrag en maatschappij & 92 & 85 & 87 & 2,9 & 12,40 \\
\hline BOL niveau 4 Totaal & Totaal & 83 & 68 & 72 & 3,4 & 12,00 \\
\hline \multirow[t]{5}{*}{ BOL 4} & Landbouw & 75 & 61 & 64 & 2,6 & 10,01 \\
\hline & Techniek & 80 & 66 & 71 & 4,2 & 12,17 \\
\hline & Economie & 79 & 55 & 63 & 5,4 & 10,33 \\
\hline & Gezondheidszorg & 90 & 82 & 83 & 1,2 & 13,65 \\
\hline & Gedrag en maatschappij & 88 & 76 & 75 & 2,1 & 12,47 \\
\hline BBL Totaal & Totaal & 80 & 73 & 85 & 1,4 & 14,29 \\
\hline BBL niveau 1 Totaal & Totaal & 70 & 36 & 73 & 7,1 & 10,66 \\
\hline BBL niveau 2 Totaal & Totaal & 82 & 62 & 83 & 2 & 12,42 \\
\hline \multirow[t]{4}{*}{$\mathrm{BBL} 2$} & Landbouw & 70 & 54 & 81 & 2,9 & 11,60 \\
\hline & Techniek & 84 & 68 & 87 & 1 & 12,93 \\
\hline & Economie & 81 & 50 & 78 & 3,2 & 10,77 \\
\hline & Gezondheidszorg & 83 & 69 & 83 & 2,2 & 14,92 \\
\hline BBL niveau 3 Totaal & Totaal & 74 & 76 & 87 & 0,9 & 14,58 \\
\hline \multirow[t]{5}{*}{ BBL 3} & Landbouw & 64 & 66 & 83 & 1,4 & 13,03 \\
\hline & Techniek & 69 & 80 & 87 & 0,5 & 14,78 \\
\hline & Economie & 68 & 58 & 78 & 2,5 & 11,23 \\
\hline & Gezondheidszorg & 85 & 86 & 92 & 0,3 & 16,71 \\
\hline & Gedrag en maatschappij & 92 & 88 & 88 & 0 & 15,72 \\
\hline BBL niveau 4 Totaal & Totaal & 90 & 83 & 87 & 0,6 & 16,26 \\
\hline \multirow[t]{5}{*}{ BBL 4} & Landbouw & 70 & 62 & 77 & 0 & 16,30 \\
\hline & Techniek & 88 & 81 & 90 & 0 & 15,91 \\
\hline & Economie & 83 & 66 & 73 & 1,5 & 12,81 \\
\hline & Gezondheidszorg & 95 & 92 & 92 & 0,1 & 18,06 \\
\hline & Gedrag en maatschappij & 96 & 92 & 88 & 3 & 16,45 \\
\hline
\end{tabular}




\section{Schoolverlaters-Meting 2019: Kernresultaten}

\section{B) HBO-Monitor}

\begin{tabular}{|c|c|c|c|c|}
\hline & & $\begin{array}{c}\text { Gevolgde opleiding achteraf: starten } \\
\text { op arbeidsmarkt } \\
\%\end{array}$ & $\begin{array}{c}\text { Gevolgde opleiding achteraf: verder } \\
\text { ontwikkelen } \\
\%\end{array}$ & $\begin{array}{c}\text { Opleiding achteraf } \\
\text { opnieuw kiezen } \\
\%\end{array}$ \\
\hline HBO Totaal & Totaal & 62 & 68 & 78 \\
\hline \multirow[t]{7}{*}{ HBO } & Landbouw & 65 & 72 & 80 \\
\hline & Onderwijs & 74 & 61 & 87 \\
\hline & Techniek & 68 & 70 & 84 \\
\hline & Economie & 58 & 65 & 70 \\
\hline & Gezondheidszorg & 69 & 73 & 83 \\
\hline & Gedrag en maatschappij & 60 & 68 & 78 \\
\hline & Taal en cultuur & 32 & 73 & 82 \\
\hline
\end{tabular}

Vervolgopleiding

\begin{tabular}{|c|c|c|c|c|}
\hline & & $\begin{array}{c}\text { Aansluiting goed/redelijk } \\
\%\end{array}$ & $\begin{array}{c}\text { Gestopt } \\
\%\end{array}$ & $\begin{array}{c}\text { Gestopt en studie gewisseld } \\
\%\end{array}$ \\
\hline HBO Totaal & Totaal & 75 & 6 & 1 \\
\hline \multirow[t]{7}{*}{ HBO } & Landbouw & 82 & 3 & 1 \\
\hline & Onderwijs & 81 & 5 & 1 \\
\hline & Techniek & 73 & 5 & 0 \\
\hline & Economie & 72 & 6 & 1 \\
\hline & Gezondheidszorg & 81 & 4 & 0 \\
\hline & Gedrag en maatschappij & 75 & 7 & 0 \\
\hline & Taal en cultuur & $x$ & 8 & 1 \\
\hline
\end{tabular}

\section{Arbeidsmarkt}

\begin{tabular}{|c|c|c|c|c|c|c|}
\hline & & $\begin{array}{c}\text { Minimaal op eigen } \\
\text { niveau } \\
\%\end{array}$ & $\begin{array}{c}\text { Eigen/verwante } \\
\text { richting } \\
\%\end{array}$ & $\begin{array}{c}\text { Aansluiting } \\
\text { goed/voldoende } \\
\%\end{array}$ & $\begin{array}{c}\text { Werkloze } \\
\text { beroepsbevolking } \\
\%\end{array}$ & $\begin{array}{c}\text { Gemiddeld } \\
\text { bruto uurloon } \\
€\end{array}$ \\
\hline HBO Totaal & Totaal & 80 & 78 & 76 & 4 & 15,20 \\
\hline \multirow[t]{7}{*}{ HBO } & Landbouw & 79 & 75 & 76 & 4,5 & 14,67 \\
\hline & Onderwijs & 92 & 90 & 86 & 1,2 & 15,42 \\
\hline & Techniek & 86 & 82 & 80 & 4,2 & 15,93 \\
\hline & Economie & 83 & 68 & 70 & 5,4 & 15,02 \\
\hline & Gezondheidszorg & 80 & 90 & 83 & 2,5 & 16,38 \\
\hline & Gedrag en maatschappij & 66 & 86 & 75 & 3 & 15,13 \\
\hline & Taal en cultuur & 65 & 63 & 69 & 4,7 & 12,03 \\
\hline
\end{tabular}




\section{Factsheet}

ROA-F-2020/7

\section{C) NAE}

\begin{tabular}{|l|l|l|l|l|}
\hline Algemeen & \multicolumn{2}{|c|}{$\begin{array}{c}\text { Gevolgde opleiding achteraf: starten } \\
\text { op arbeidsmarkt } \\
\text { \% }\end{array}$} & $\begin{array}{c}\text { Gevolgde opleiding achteraf: verder } \\
\text { ontwikkelen } \\
\%\end{array}$ & $\begin{array}{c}\text { Opleiding achteraf } \\
\text { opnieuw kiezen } \\
\%\end{array}$ \\
\hline W0 Totaal & Totaal & 56 & 74 & 82 \\
\hline W0 & Landbouw & 58 & 79 & 76 \\
\hline & Natuur & 57 & 79 & 85 \\
\hline & Techniek & 67 & 80 & 81 \\
\hline & Gezondheidszorg & 71 & 80 & 83 \\
\hline & Economie & 68 & 76 & 84 \\
\hline & Recht & 59 & 74 & 81 \\
\hline & Gedrag en Maatschappij & 40 & 68 & 77 \\
\hline
\end{tabular}

\section{Arbeidsmarkt}

\begin{tabular}{|l|l|c|c|c|c|}
\hline & Minimaal op eigen niveau & Eigen/verwante richting & $\begin{array}{c}\text { Werkloze } \\
\text { beroepsbevolking }\end{array}$ & $\begin{array}{c}\text { Gemiddeld } \\
\text { bruto uurloon } \\
€\end{array}$ \\
\hline W0 Totaal & Total & $\%$ & $\%$ & 4,6 & 17,92 \\
\hline & Landbouw & 71 & 74 & 7,1 & 14,61 \\
\hline & Natuur & 69 & 77 & 4,4 & 17,69 \\
\hline & Techniek & 74 & 81 & 4,5 & 18,02 \\
\hline & Gezondheidszorg & 77 & 78 & 21,12 & 18,8 \\
\hline & Economie & 89 & 87 & 2,3 & 17,67 \\
\hline & Recht & 69 & 73 & 6,1 & 17,04 \\
\hline & Gedrag en Maatschappij & 78 & 77 & 5,6 & 16,7 \\
\hline
\end{tabular}




\section{Colofon}

( ) Researchcentrum voor Onderwijs en Arbeidsmarkt Niets uit deze uitgave mag op enige manier worden verveelvoudigd zonder voorafgaande schriftelijke toestemming van de directeur van het ROA.

\section{Researchcentrum voor Onderwijs en Arbeidsmarkt} Maastricht University

School of Business and Economics

secretary-roa-sbe@maastrichtuniversity.nl

www.roa.nl

\section{Vormgeving}

ROA secretariaat, Maastricht

september 2020

ISSN: 2667-0488 